\title{
Analysis of Actin and Focal Adhesion Organisation in U2OS Cells on Polymer Nanostructures
}

\author{
Jakob B. Vinje ${ }^{1,3^{*}} \mathbb{B}$, Noemi Antonella Guadagno ${ }^{2}$, Cinzia Progida ${ }^{2}$ and Pawel Sikorski ${ }^{1}$
}

\begin{abstract}
Background: In this work, we explore how U2OS cells are affected by arrays of polymer nanopillars fabricated on flat glass surfaces. We focus on describing changes to the organisation of the actin cytoskeleton and in the location, number and shape of focal adhesions. From our findings we identify that the cells can be categorised into different regimes based on their spreading and adhesion behaviour on nanopillars. A quantitative analysis suggests that cells seeded on dense nanopillar arrays are suspended on top of the pillars with focal adhesions forming closer to the cell periphery compared to flat surfaces or sparse pillar arrays. This change is analogous to similar responses for cells seeded on soft substrates.

Results: In this work, we explore how U2OS cells are affected by arrays of polymer nanopillars fabricated on flat glass surfaces. We focus on describing changes to the organisation of the actin cytoskeleton and in the location, number and shape of focal adhesions. From our findings we identify that the cells can be categorised into different regimes based on their spreading and adhesion behaviour on nanopillars. A quantitative analysis suggests that cells seeded on dense nanopillar arrays are suspended on top of the pillars with focal adhesions forming closer to the cell periphery compared to flat surfaces or sparse pillar arrays. This change is analogous to similar responses for cells seeded on soft substrates.

Conclusion: Overall, we show that the combination of high throughput nanofabrication, advanced optical microscopy, molecular biology tools to visualise cellular processes and data analysis can be used to investigate how cells interact with nanostructured surfaces and will in the future help to create culture substrates that induce particular cell function.
\end{abstract}

Keywords: Nanostructures, Bionanotechnology, Cell-nanostructure interactions, Focal adhesion, actin cytoskeleton

\section{Background}

In vivo, cells typically reside in a a complex 3D environment called extracellular matrix (ECM). The ECM not only serves as a structural scaffold for the cells, it is also a conveyor of biomechanical and biochemical signals and thus regulates a range of processes such as tissue morphogenesis, homeostatis and differentiation. It is

\footnotetext{
*Correspondence: jakob.vinje@ntnu.no

${ }^{1}$ Department of Physics, Norwegian University of Science

and Technology (NTNU), Trondheim, Norway

Full list of author information is available at the end of the article
}

composed of water, polysaccharides and proteins [1-4], and the composition varies between tissue types.

Motivated by the need of creating cell culturing models that better represent in vivo conditions, researchers have increasingly started to study cell behaviour also in 3D matrices and in "semi-3D" systems. A number of differences in cell phenotypes between flat substrates and systems with higher dimensionallity have been identified $[5,6]$. For example, characteristics such as viability, proliferation, differentiation and morphology are known to differ between cells on flat surfaces and cells embedded in $3 \mathrm{D}$ matricies $[3,7]$. 
In vivo-like substrates range from "semi-3D"/2.5D substrates, such as flat surfaces decorated with various nanostructures to "true-3D" systems such as collagen gels or matrigel matrices [8-11]. In addition, controlled positioning of ligands on surfaces may give new insights into how cells interact with various chemical patterns [1214]. Also mechanical factors such as structure stiffness or even surface chemistry have been shown to influence cellular function [15-17]. To this end, a large number of different substrates for cellular studies have been developed [3, 18-22].

It has also been suggested that $3 \mathrm{D}$ culturing systems more precisely could predict the in vivo effect of a drug and thus these systems could find applications in drug discovery [16, 23, 24]. Precisely controlling nanoscale topographical patterns can also be used to regulate cell morphology. For example, wrinkles and grooves can be used to recreate the striated alignment of cardiomyocytes and thus better represent physiologically relevant conditions to model various diseases $[25,26]$.

The cytoskeleton of the cell is connected to the ECM is facilitated by focal adhesions (FAs), a multiprotein complex including cell surface integrins and scaffold proteins. Depending on a complex set of regulatory mechanisms, the FAs form and disassemble at a turnover rate needed for forward movement, for example in cell migration. The FAs are known to exert mechanical force on the ECM, and conversely the ECM exerting force on the cells is known to influence integrin affinity and avidity in the membrane [27].

One of the proteins known to be an integral part of the FAs is vinculin. It is one of the linker proteins involved in anchoring F-Actin to the integrin-complex. Lack of vinculin alters cell morphology, adhesion and motility [28], and impairs the cells ability to transduce force to the substrate [29-31]. Vinculin is not only involved in the mechanical connection of the actin cytoskeleton to the integrin-complexes, it also has the ability to crosslink and bundle actin filaments [32-34], modify existing actin bundles [35], cap actin filaments, nucleate new actin polymerisation sites [36] and recruit actin modifiers [37].

Cells respond to the $3 \mathrm{D}$ matrices by changing the number and type of cell-substrate adhesion and induce changes in the spatial organisation of the cytoskeleton. These changes in turn influence distribution, size and dynamics of the formed adhesions [4, 38-41]. This rearrangement may lead to changes in cell proliferation, morphology and motility [42].

In order to understand the influence of complex 3D environments on cells, there is a need to develop new model systems where cellular processes can be studied and compared to flat controls. As cellular response is known to depend on physical, mechanical and chemical characteristics of the culturing substrate, it is desirable to fabricate cellular substrates with precisely controlled properties [43-45]. Additionally, it is highly advantageous if the cells and the substrate easily can be studied using already established analysis techniques such as optical microscopy.

One type of substrate that has recently gained attention are flat surfaces decorated with nano-pillars or nanowires [18, 21, 46-53]. Compared to for example hydrogels, these structured surfaces do not mimic the true 3D environment, but have well defined surface topography. These substrates are typically referred to as being $2.5 \mathrm{D}$. Such systems have already been applied to facilitate delivery of biologically relevant molecules into cells [54, 55], to monitor enzymatic activity [56], to test nuclear mechanics [57] and to study how tuning the membrane curvature influence various cell-membrane related processes [58-60]. By fabricating nanostructures on transparent substrates, it is possible to integrate this approach with optical microscopy.

The number possible combinations of different cell lines, nanostructure type and geometry is high, and examples from the literature are abundant. $\mathrm{Li}$ et al. described cell behaviour on surfaces decorated with randomly positioned gallium phosphide nanostructures and quantified the fraction of cells with large FAs [61]. The cell and FA morphology was investigated on surface with various area densities of nanowires. The results indicated that cells seeded on low-density surfaces were in contact with the substrate and formed large FAs around the cell edges. Large FAs were detected in a high fraction of cell on these arrays. For high nanowire areal densities and, cells were suspended on the top of the nanowire arrays and point-like FAs under the cells were observed. A lower fraction of cells on these arrays showed large FAs compared to cells on surface with low nanowire area density.

Buch-Månson et al. studied cell-nanostructured surface interactions for silicon nanocolumn arrays randomly position on a $\mathrm{Si}$ substrate [62]. In the used fabrication process, areal density but not pillar-pillar distance was controlled. Investigation of FAs showed that cells on the arrays with the intermediate areal density had the largest number of FAs that also had the most asymmetric shape. It was suggested that some of these FAs formed on the sidewalls of the nanocolumns. This was not observed for surfaces with low and high areal nanocolumn density.

In previous work we have described detailed protocols for fabrication of SU-8 polymer nanostructures on flat glass surfaces [63], and explored cell behaviour for two different cell lines on these surfaces $[45,48]$. In this work, we use electron beam lithography (EBL) to fabricate surfaces decorated with vertically aligned SU-8 polymer structures to study changes in actin cytoskeletal and 
FA organisation in the osteosarcoma epithelial cell line U2OS. We perform both qualitative and quantitative analysis of the changes induced by the surface with different topological cues.

\section{Results}

Using previously established protocols, we have fabricated glass cover-slips decorated with precisely defined arrays of vertically oriented SU-8 nanopillars (NP) with variable separation and defined geometry [63]. Surfaces with NP areal densities of 456, 205, 115 and $29 \mathrm{NPs} / 100 \mu \mathrm{m}^{2}$ (corresponding to pitches of $500 \mathrm{~nm}, 750 \mathrm{~nm}, 1000 \mathrm{~nm}$ and $2000 \mathrm{~nm}$ ) were used. First we examine general trends in cell morphology, structure of actin cytoskeleton and cell-substrate interactions. We follow this by quantitative comparison of cell and FAs morphology on various nanostructured substrates and flat glass controls. We combine high resolution microscopy with high throughput fabrication to do qualitative analysis of at least $\approx 100$ cells for each surface type, with imaging after $24 \mathrm{~h}$ and $48 \mathrm{~h}$. In total we analyse $>400$ high resolution images and $203 \mathrm{D}$ data sets.

Figure 7 shows a schematic representation of the NP arrays (A, B) and electron microscopy images of fabricated substrates $(C, D)$. Glass slides containing nanofabricated structures were mounted using paraffin under hollow bottom, $35 \mathrm{~mm}$ culture with the structures pointing upwards. Top-down and titled side-view electron microscopy images shown, in Fig. 1C,D show nano-pillar arrays of with pitch and height of $1000 \mathrm{~nm}$. Table 1 shows geometric parameters of arrays used in this work, their classification, as well as the corresponding NP area number density. We classify NP arrays into dense and sparse depending on observed cell adhesion behaviour (see below).

Figure 1 shows representative U2OS cells cultured on glass (A) and nanostructured surface (B-F) for $24 \mathrm{~h}$. The cells have been co-transfected with pCMV-LifeAct-GFP and pTAG-RFP-Vinculin, that allows the visualisation of

Table 1 Overview over pillar arrays used for the study of actin organisation and FA localisation

\begin{tabular}{lllll}
\hline Height [nm] Pitch $[\mathrm{nm}]$ Category & $\begin{array}{l}\text { Density } \\
{\left[\mathbf{N P s} / \mathbf{1 0 0} \boldsymbol{\mu m}^{\mathbf{2}}\right]}\end{array}$ & $\begin{array}{l}\text { Exposure time } \\
{\left[\mathbf{m m}^{\mathbf{2}} / \mathbf{m i n}\right]}\end{array}$ \\
\hline 500 & 500 & Dense & 456 & 0.7 \\
& 1000 & Sparse & 115 & 1.5 \\
1000 & 750 & Dense & 205 & 0.9 \\
& 1000 & Dense & 115 & 1.5 \\
& 2000 & Sparse & 29 & 4.0 \\
\hline
\end{tabular}

Arrays with a given NP height and array pitch are categorised into either Dense or Sparse and the corresponding density of NPs is reported
F-Actin and vinculin through production of flourescent LifeAct-TagGFP2 (hereafter: LifeActGFP) and TagRFPvinculin fusion proteins respectively. F-actin network and vinculin rich areas in FAs are clearly detected. At the cell periphery, the LifeActGFP signal is in close proximity to the membrane and therefore we use this signal to visualise cell morphology. Signal from SU-8 NPs is shown in blue (see "Experimental" section).

Preliminary tests using transfected cells showed that cells seeded on both glass and structured surfaces appeared to be fully spread after approximately $6 \mathrm{~h}$. No clear differences in cell spreading between the different surfaces was observed, and visual inspection revealed no signs of decreased cell viability due to the pillar arrays at this point or in later experiments. In the following experiments cells were transfected $6 \mathrm{~h}$ after seeding, and then imaged $24 \mathrm{~h}, 48 \mathrm{~h}$ after transfection, corresponding to transfection $30 \mathrm{~h}, 54 \mathrm{~h}$ after seeding. In the following, these two time points will be referred by the observation time after seeding, that is $24 \mathrm{~h}, 48 \mathrm{~h}$.

Cells were seeded on NP arrays with height $500 \mathrm{~nm}$, $1000 \mathrm{~nm}$ and pitch $750 \mathrm{~nm}, 1000 \mathrm{~nm}, 2000 \mathrm{~nm}$. After the initial spreading, cells were observed to be either round or elongated, similar to the situation on flat surfaces. This general morphology was found to be consistent over multiple experiments. Cells seeded on sparse NP arrays generally had a shape similar to the cells on glass surface, see Fig. 1F depicting a representative cell on a $2000 \mathrm{~nm}$ pitched array. F-actin fibres were present also at the base of the NPs and in proximity of the glass surface, indicating that the cells were able to access the area close to the substrate. As observed previously $[45,62,64]$, cells on dense arrays typically appeared to be suspended on top of the NPs (Fig. 1B, D, E). Cells on dense arrays appear to have less prominent $\mathrm{F}$-actin close to the glass surface, indicating that the actin fibres were not formed between pillars in proximity to the substrate. The relation between NP height and separation determined if the cells adhered to the substrate or were suspended on the top of the NP array. This is for example illustrated in Fig. $1 \mathrm{C}$ where shorter NPs lead to the cell contacting the substrate, whereas longer NPs hindered contact, Fig. 1E. These observations of actin fibres were further corroborated by z-stacks performed for some of the surfaces, as presented in Fig. 2.

To obtain a more detailed understanding on how cells adhere to the structured and non-structured surface, we evaluated distribution of FAs as visualised by the presence of TagRFP-vinculin fusion protein. Cells on flat surfaces typically formed elongated FAs distributed underneath the whole cell body, as shown in Fig. 1A.

On sparse arrays, U2OS were able to contact the glass surface between NPs and adhered similarly to cells on 

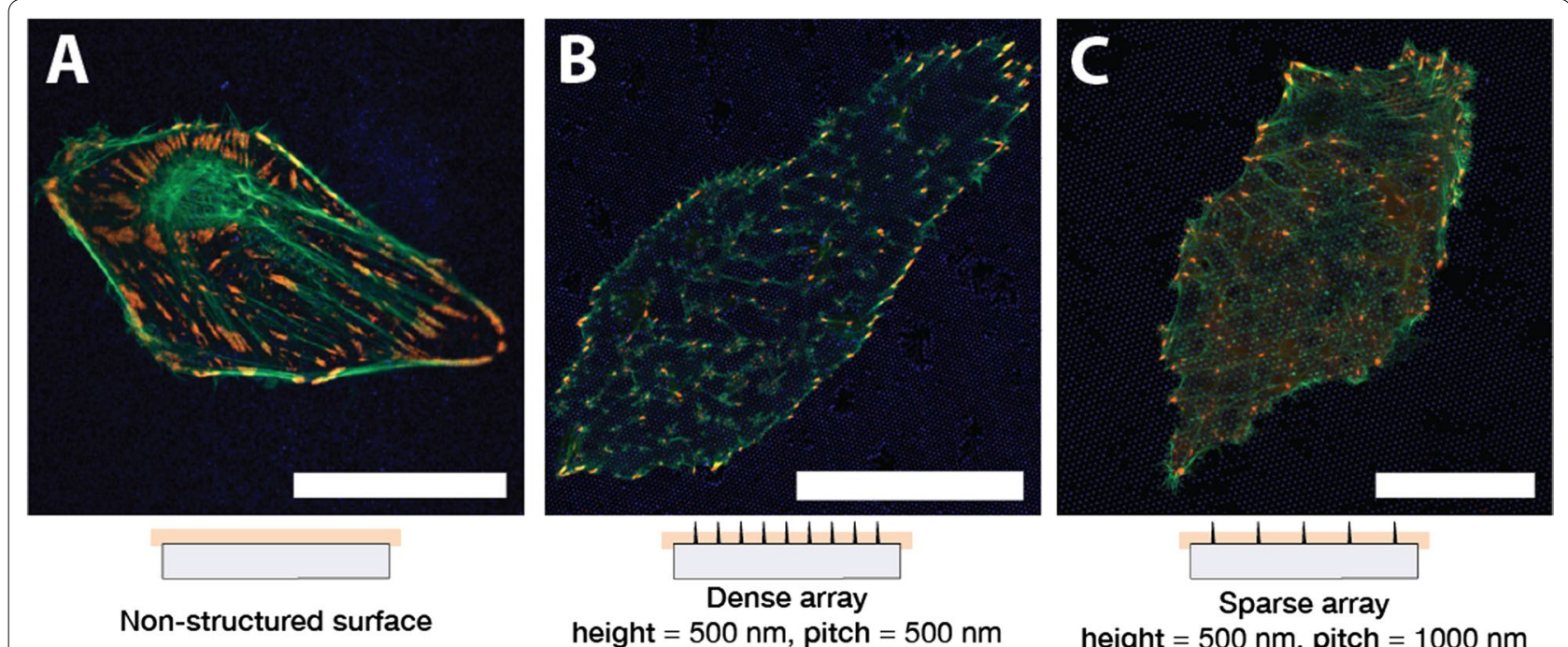

Non-structured surface
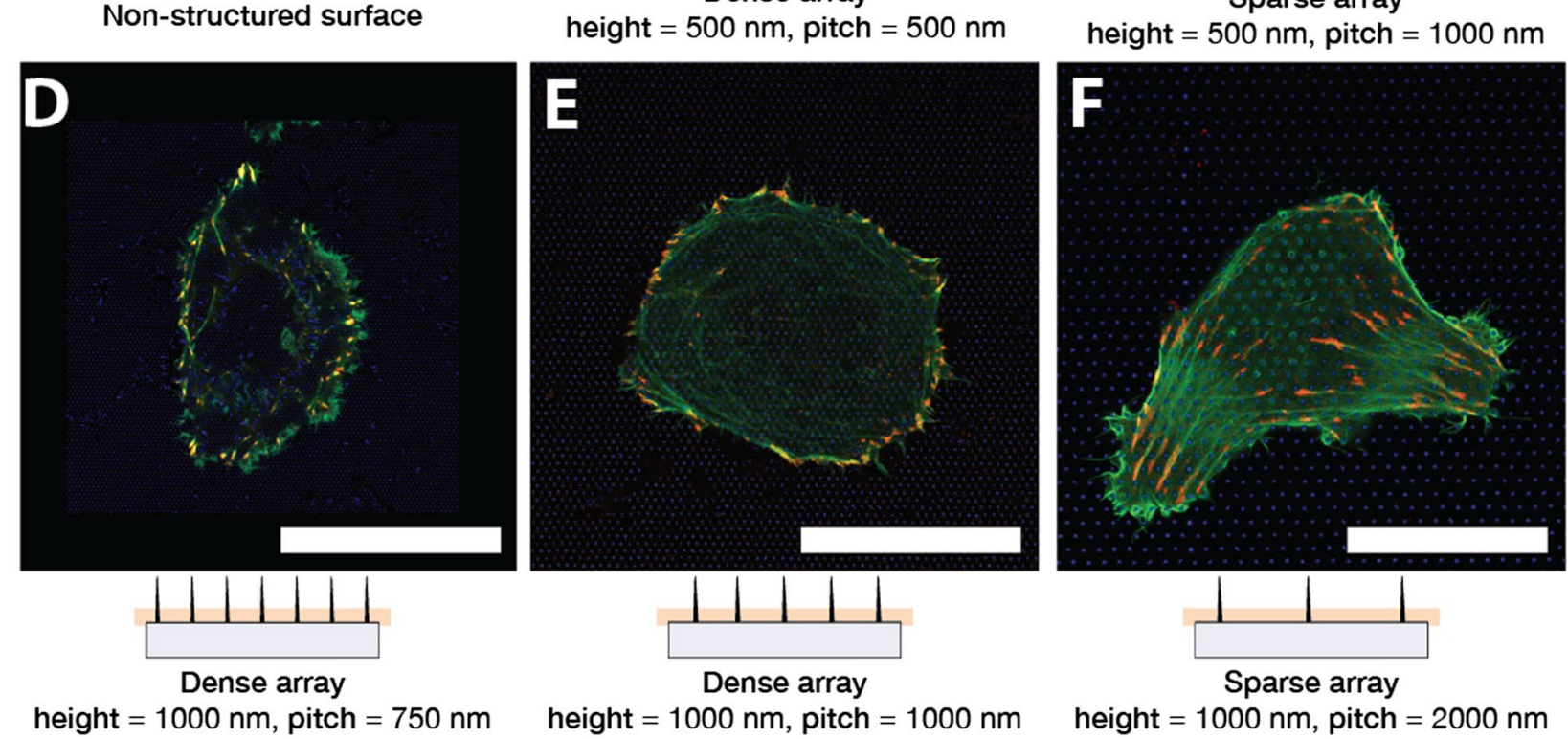

Fig. 1 U2OS expressing fluorescent LifeActGFP (green) and TagRFP-vinculin (red) on different surface types. Yellow colouring indicates overlapping signals from LifeActGFP and TagRFP-vinculin channels. Below each micrograph a schematic side-view of the corresponding NP array is shown, together with the approximate position of the acquisition plane. Cells imaged on $\mathbf{A}$ non-structured flat glass surface and on pillar arrays with different array pitch and structure heights: B $500 \mathrm{~nm}$ pitch and $500 \mathrm{~nm}$ height, C $1000 \mathrm{~nm}$ pitch and $500 \mathrm{~nm}$ height, D $750 \mathrm{~nm}$ pitch and $1000 \mathrm{~nm}$ height, $\mathbf{E} 1000 \mathrm{~nm}$ pitch and $1000 \mathrm{~nm}$ height, and F $2000 \mathrm{~nm}$ pitch and $1000 \mathrm{~nm}$ height. All images presented are of representative cells. Scalebar $25 \mu \mathrm{m}$. Note that $\mathbf{C}$ has a different scale than the other images

glass, shown in Fig. 1C, F. For these NP arrays, FAs formed on glass in-between NPs, and the F-actin signal was also detected in the image acquired close to the base of the NPs. This indicated that the cells were able to bend the membrane around the nanostructures. Cells on denser arrays however, such as $750 \mathrm{~nm}, 1000 \mathrm{~nm} \mathrm{~nm}$ separation and $1000 \mathrm{~nm}$ height, were clearly hindered from adhering to the substrate between the nanostructurues, as shown in images Fig. 1D, E that was acquired close to the base of the NPs. However, around the periphery, the cells were typically able to attach to the substrate between the nanostructures forming FAs, often directed by the symmetry of the underlying pillar array.

Cells spreading on NP arrays with shorter length, and with an inter-pillar spacing of $1000 \mathrm{~nm}$ formed adhesions both towards the periphery and under the cell body. The F-actin fibre orientation was directed by the symmetry of the underlying array, as shown in Fig. $1 \mathrm{C}$. However, the location and orientation of vinculin containing FAs did not exhibit any clear pattern, with FA forming in-between NPs. 


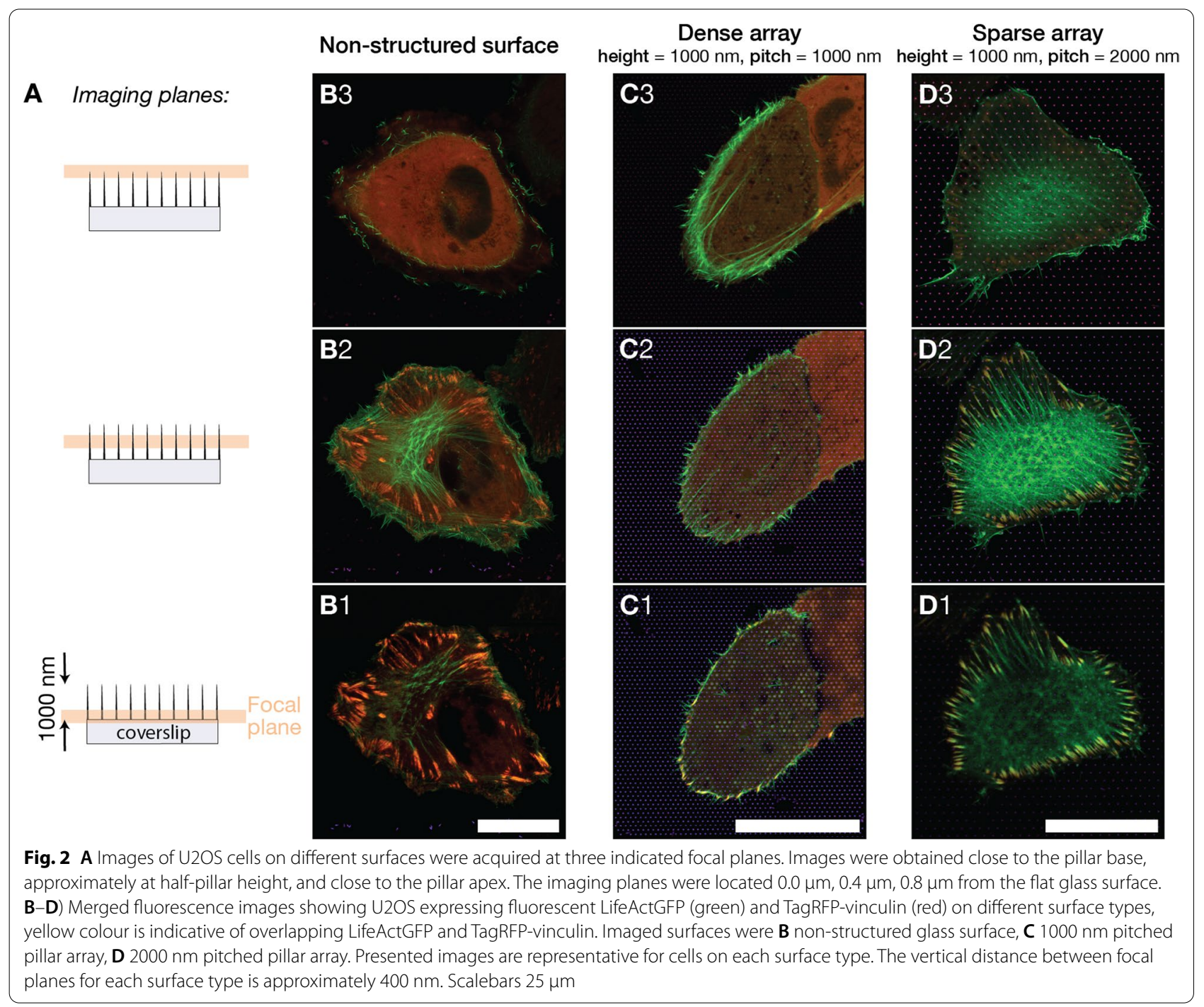

U2OS cells on $500 \mathrm{~nm}$ pillars with inter-pillar distance of $500 \mathrm{~nm}$ generally formed fewer and smaller adhesions compared to the planar surface as shown in Fig. 1B. For cells seeded on this array, actin fibres were primarily observed in proximity to the glass surface at positions where they terminated in FAs. Again, this is a sign that the actin network was hindered from contacting the surface, and the cells were therefore assumed to be suspended on top of the array. However, cells appeared to have more intact F-actin network forming above the pillars. Parts of the actin network that was observed inbetween the pillars, appeared to align with structures in the underlying NP array. This can be seen in Fig. 1B, as F-actin fibres and FAs predominantly form along to one of the lattice direction, i.e. parallel to open "lines", of the pillar array.

On both dense and sparse arrays, we observed "ringlike" F-actin structures that formed around NP that protrudes upwards into the cell body. The F-actin ring structure appeared to be more prominent on sparse arrays, as shown in Fig. 1E, F.

Based on the results presented above, we have selected three surfaces for a more detailed and quantitative description of cell morphology and FAs. We study cells on dense arrays (pitch $1000 \mathrm{~nm}$, length $1000 \mathrm{~nm}$ ), sparse arrays (pitch $2000 \mathrm{~nm}$, length $1000 \mathrm{~nm}$ ) and compare the results with cells on flat glass surfaces used as control.

By employing the Airyscan detector together with the dedicated image post-processing, we were able to perform imaging with an xy-resolution of about $140 \mathrm{~nm}$ and z-resolution of about $400 \mathrm{~nm}$ [65]. Figure 2 shows images of cells on the three surfaces, with imaging planes separated by approximately $400 \mathrm{~nm}$. The investigation of $\mathrm{F}$-actin bundles at different $z$. Cells on flat surface had a clearly visible F-actin network at the same focal plane or right above the FAs, (see Fig. 2-B2). For cells on dense 
arrays, the F-actin network was found on a higher focal plane within the cell compared to the FA plane, which was in contact with the glass support (Fig. 2-C1 and C2/ C3). For cells on sparse arrays, the situation was similar to the cell on glass controls and actin network and FAs were detected at the same height (Fig. 2-D2). This data support the initial observation that cells on sparse arrays attached the surface between the structures, whereas cells on dense arrays were primarily able to adhere to the surface around the cell periphery.

To analyse and quantify the differences in FAs and cell morphology for the three selected surfaces a Python

Table 2 Number of observations for cells $\left(n_{\text {cell }}\right)$ and for FAs $\left(n_{\text {FA }}\right)$ used in the quantitative analysis

\begin{tabular}{llll}
\hline Surface & Time $[\mathrm{h}]$ & & \multicolumn{2}{l}{ Observations } \\
\cline { 3 - 4 } & & $\boldsymbol{n}_{\text {cell }}$ & $\boldsymbol{n}_{\mathrm{FA}}$ \\
\hline Flat & 24 & 29 & 1379 \\
& 48 & 69 & 1280 \\
Pillars 2000 nm & 24 & 121 & 2513 \\
\multirow{2}{*}{ Pillars 1000 nm } & 48 & 94 & 1307 \\
& 24 & 80 & 814 \\
& 48 & 30 & 451 \\
\hline
\end{tabular}

Reported values correspond to the total number of cells identified by the image analysis script for each time point ( $24 \mathrm{~h}$ and $48 \mathrm{~h}$ ) and surface type (flat surface, $1000 \mathrm{~nm}$ pillar array and $2000 \mathrm{~nm}$ pillar array) based image analysis script was used (see "Experimental"). For the quantitative analysis, more than 300 highresolution images were analysed. In these images, $>400$ cells and $>7700$ FAs were identified, Table 2 lists the number of detected cells and FAs for the three surface types included in the analysis. For all surfaces, cells were imaged both $24 \mathrm{~h}, 48 \mathrm{~h}$ after transfection. In the following analysis, geometrical parameters such as surface area, circularity and aspect ratio for cells on 3 surface types and after $24 \mathrm{~h}, 48 \mathrm{~h}$ are compared. Additional analysis can be found in the Supplementary Information. Surface area, circularity and aspect ratio for cells are shown in Fig. 3 and for number of FAs, combined FA area per cell and fraction of FA area to cell in Fig. 4. The geometrical parameters were defined as described in the "Experimental" section.

Figure 3 summarises data collected for both flat and structured surfaces. As shown in Fig. 3A, significant differences in the cell area were observed after $24 \mathrm{~h}$ cell culture. However, after $48 \mathrm{~h}$, there was no significant difference between average cell area on studied surfaces. When considering cell circularity (Fig. 3B), no significant differences were detected between different surfaces, except between cells seeded on dense and sparse pillars imaged after $24 \mathrm{~h}$. Cells on all three surfaces had the same average aspect ratios, as presented in Fig. 3C.

Figure 4 shows the distribution of the number of detected FAs per cell, total surface area of FAs in each cell

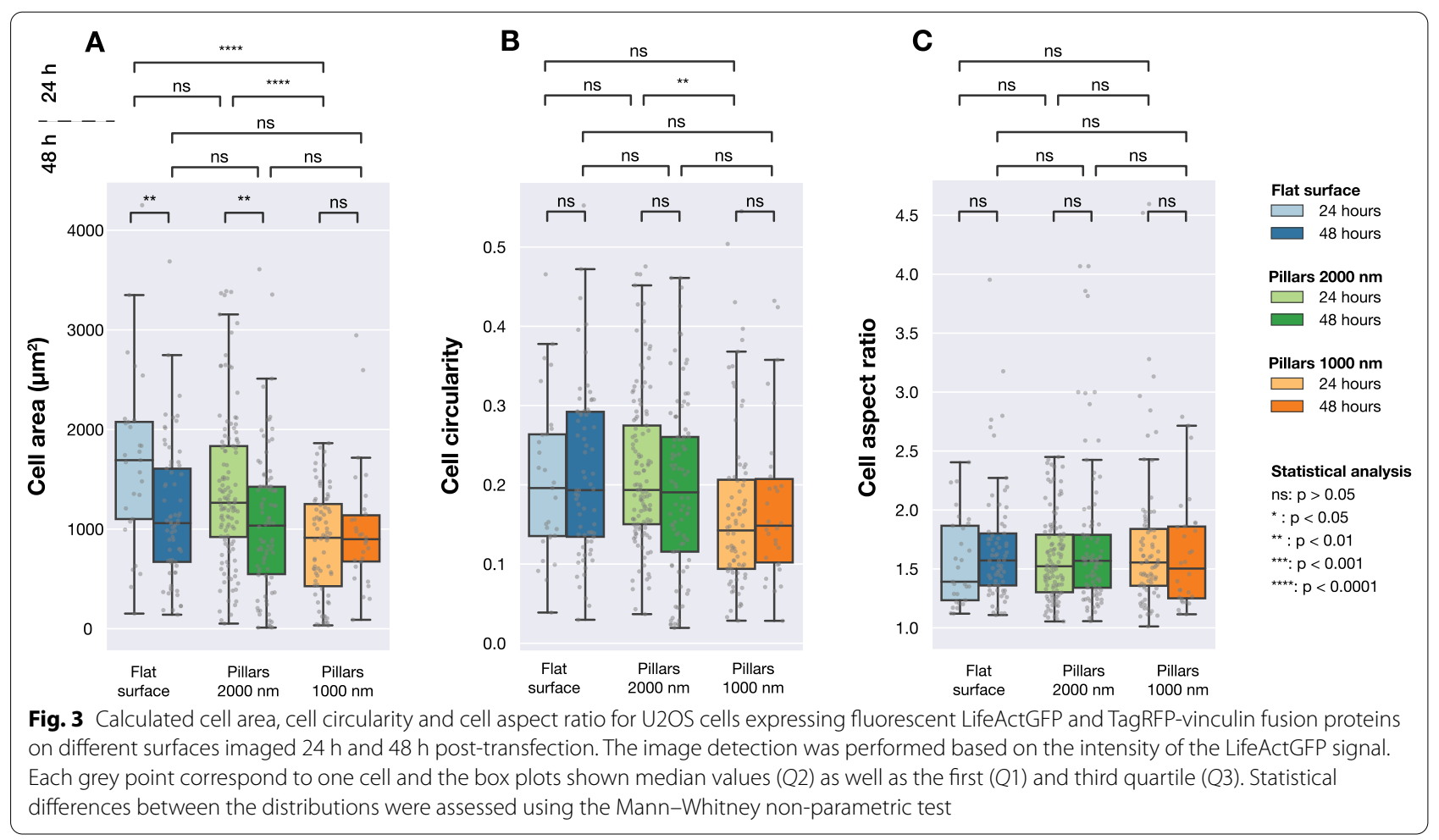




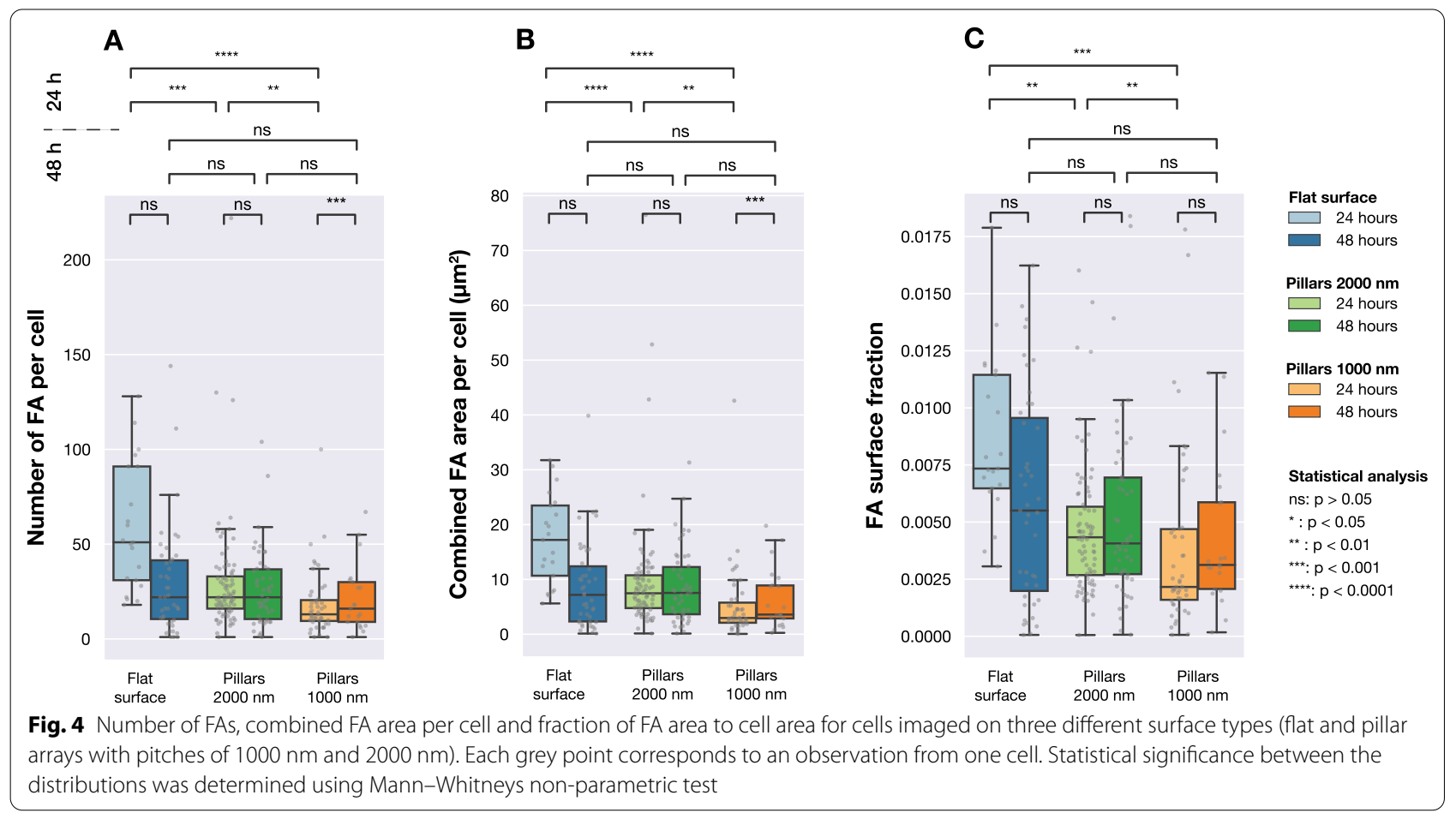

and the ratio of FA area to cell area. After $24 \mathrm{~h}$ the number of FAs formed by cells on the three different surfaces was significantly different. As shown in Fig. 4B, the total FA surface area per cell was different for cells seeded on flat and structured surfaces. The same can be seen when comparing the relative amount of FAs (the total area of detected FAs divided by the total cell area) for the different surfaces, as shown in Fig. 4C.

However, after $48 \mathrm{~h}$ of culture, significant differences between cell populations were no longer observed. When considering number of FAs per cell, combined FA area per cell or FA surface fraction, no differences between the three surfaces were found.

To understand whether the presence of NPs influence the localisation of FAs in the cell, we performed further analysis using the location of the FAs. Microscopy data indicated that FAs in cells on dense NP arrays were located closer to the cell periphery, as indicated by Figs. 1 and 2. To quantify this trend, we calculated the shortest distance from each FA to the cell edge. This was performed as illustrated in Fig. 5. F-actin was used to determine location of the periphery and by constructing distance maps, the distance between each centre of a detected FA to the cell periphery was calculated. To account for differences in cell sizes, we normalised the distances between the detected cell edge and FA by the maximum distance from the edge to the geometric centre for each cell (a distance that is equivalent to radius for cells that have a circular shape). Data normalised by the maximum distance is presented in Fig. 6 and Table 3. For cells on flat surfaces, the FAs are distributed more towards the centre of the cell, whereas on both on sparse $2000 \mathrm{~nm}$ arrays and dense $1000 \mathrm{~nm}$ arrays, the FAs are located closer to the cell periphery. This effect is most notable for dense arrays with $1000 \mathrm{~nm}$ pitch. Results of an alternative normalisation approach, where the FA locations were normalised by cell surface area, are included in Supplementary Information. This data shows he same qualitative trends as the data normalised by the maximum distance to the edge in each cell presented in Fig. 6.

\section{Discussion}

Organisation of actin cytoskeleton and formation of adhesions are processes studied extensively on flat surfaces. The present study was designed to investigate and quantify changes in organisation of the actin cytoskeleton and focal adhesions on nanopillar arrays. In this study we have not investigated how nanopillar arrays effect cell migration. However, we expect that cells on the dense arrays might have higher motility, as observed previously on the same pillar arrays for embryonic mouse fibroblasts [45].

Allowing the cells to spread and adhere to the surface for an extended period of time, makes it possible to observe the actin cytoskeleton organisation and the 


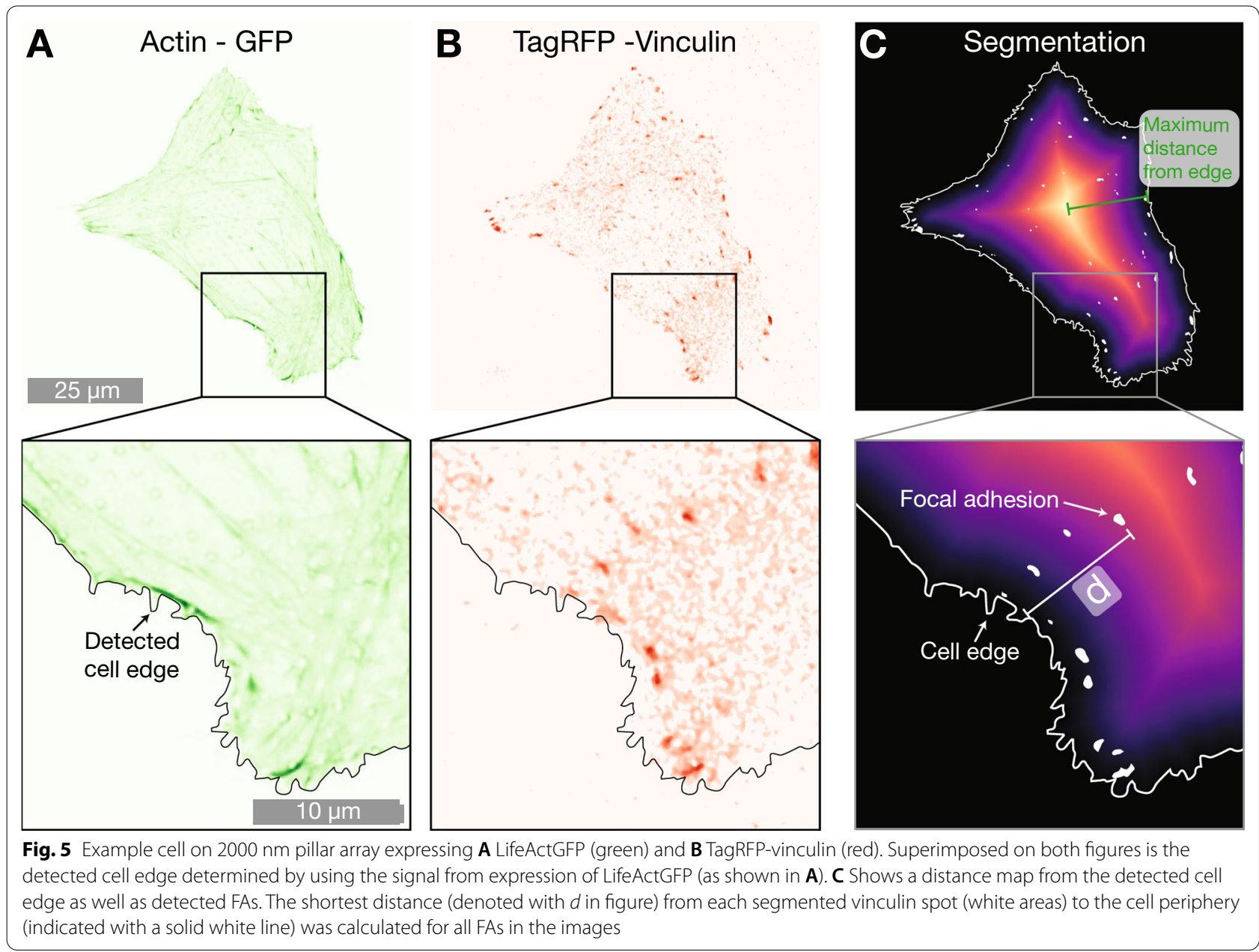

presence of fully matured FAs. $24 \mathrm{~h}$ after seeding, we observe significant differences in cell area, circularity and aspect ratio for cells seeded on the surfaces. However, no significant differences were detected after $48 \mathrm{~h}$, indicating that the cells after $24 \mathrm{~h}$ have not yet fully adhered to the surfaces, and that the nanostructures mainly influences the FA organisation before they are fully matured. Neither after $24 \mathrm{~h}$ nor after $48 \mathrm{~h}$ is any FA formation on top or on the sides of the NPs observed.

Changes in the actin cytoskeleton organisation are also connected how a cell interacts with the surroundings. For example, both stress fibres and FAs grow when subject to stretching and appear to be functional interdependent [66]. Others have reported that rounder cells and FA localisation around edges are often observed for cells seeded on soft or compliant surfaces [67]. In our results, we observe a similar trend. Cells on dense arrays tend to show fibres around the cell edge, such as shown in Figs. 1E or 2B. FAs appear to form close to the cell edge for these cells. We speculate that when cells lack a flat surface, such as when the cells are suspended on top of the pillars, the FAs distribution resembles FAs on soft substrates, such as used by Prager-Khoutorsky and co-workers [67].

From our results, we observe that cells suspended on top of the pillars do appear to have a developed actin network above the pillars, but without FAs forming on the pillars themselves. For cells on sparse arrays however, cells appear to be less influenced by the NPs and both actin network and FAs appear more "flat-surface like".

The interaction between FAs and actin cytoskeleton is complex and still not fully characterised. FAs linking the actin cytoskeleton to the ECM is known to act as traction points and to promote stress fibre formation in the cells. Conversely, actin fibres are again influencing the organisation and maturation of FAs. Numerous studies describe how cells tend to be suspended on top of dense NP arrays $[61,62,68]$ and how cell membranes interact with single NPs [69-71]. These observations are corroborated by theoretical studies [64] and the cellular behaviour on pillars is fairly well understood. 

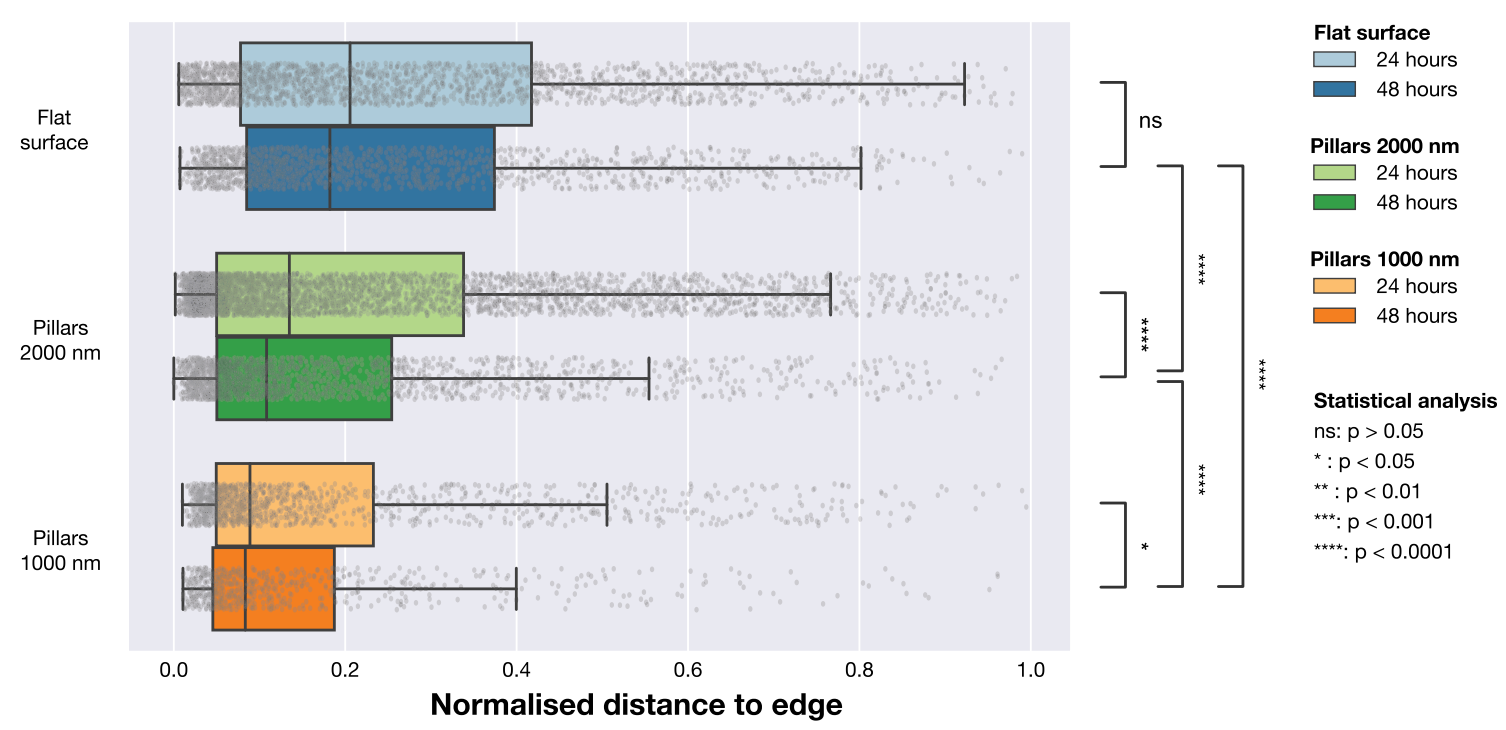

Fig. 6 Distribution of FAs positions in relation to the closest cell edge normalised by the maximum distance from geometric centre of the cell to edge. Distances was obtained by calculating the distance from each observed FA to the cell edge defined by the LifeActGFP signal and plotted for the three surface types at $24 \mathrm{~h}$ and $48 \mathrm{~h}$. Grey points represent individual observations of FAs and their distributions are summarised in the box plots. To test the likelihood that the FAs from the different surfaces and time points were from the same distribution, Mann-Whitney tests were performed on all distributions with significance levels denoted in the figure

Table 3 Distance from the centre of a detected FA to the closest edge of cell defined by the LifeActGFP signal

\begin{tabular}{llll}
\hline Surface & Time $[\mathrm{h}]$ & $\boldsymbol{n}_{\mathrm{FA}}$ & $\begin{array}{l}\text { Distance }\left[\boldsymbol{\mu m}^{2}\right] \\
\text { Q2 }[Q 1, \mathrm{Q} 3]\end{array}$ \\
\hline Flat & 24 & 1379 & $3.1[1.2,7.7]$ \\
& 48 & 1280 & $2.5[1.1,5.8]$ \\
$2000 \mathrm{~nm}$ & 24 & 2513 & $1.9[0.8,5.2]$ \\
& 48 & 1307 & $1.4[0.8,3.2]$ \\
$1000 \mathrm{~nm}$ & 24 & 814 & $0.9[0.6,2.1]$ \\
& 48 & 451 & $1.1[0.7,2.1]$ \\
\hline
\end{tabular}

Number of observations used in analysis is given as $n_{\mathrm{FA}}$. Values reported for the distance are median values (Q2) as well as the first (Q1) and third quartile (Q3)

The mechanism behind FAs formation and attachment to the substrate around the cell edge on dense arrays remains unclear. In this respect, comparison with cells on a soft substrate is particularly interesting. For soft substrates, actin fibres are organised in a ring like fashion close to the cell edge and FAs form around the cell periphery [67]. On the nanopillar arrays similar type of architecture is observed, but the actin fibres are typically shorter. Similar qualitative trends in terms of actin organisation and FA formation were observed by Li et al. for cells seeded on random nanowire arrays made from gallium phosphide [61].

In our studies we also observed formation of F-actin rings around NPs. The formation of F-actin rings around NP has previously been described for fibroblasts on similar surfaces [45] and for U2OS cells on nanostructures with a range of structure sizes [58].

Contrasting our results to other studies highlight an important aspect of studies on cellular response to NP arrays: cellular response may vary considerably depending on cell type, NP material, NP geometry and as well as other parameters. For example, Buch-Månson et al. studied fibroblasts and investigations of FAs showed that cells suspended on arrays with intermediate NP density had the highest number of FAs. In our results we do not see a similar trend. However, these studies cannot be directly compared as Buch-Månson et al. studied another cell line using a system with different array geometry, surface porosity and NPs length [62].

There are also studies describing the effect FAs placement has on cells [41]. By modelling cells on planar substrates Stolarska et al. suggest that the cells can control intra-cellular stresses by three mechanisms: FA position, FA size and attachment strength. FAs around the periphery allows the cells to be more sensitive to changes in the micro-environment. This could also be an underlying mechanisms for cells on NPs. Yet, it is not obvious that the results for the planar substrate are directly transferable to NP decorated surfaces.

Cell-interactions with the surrounding environment, for flat substrate, NPs arrays or in vivo ECM, are regulated by a complex set of relations between actin organisation, membrane mechanics, cell dynamics and contact 
with FAs. To further explore these relations, applying flat surfaces structured with NPs could be one promising approach. Such surfaces may also aid in exploring discrepancies in the cellular response to environmental cues between different cell lines.

\section{Conclusions}

In order to create more physiologically relevant systems for cellular studies, a plethora of 3D and 2.5D approaches have been proposed. One approach is to use flat-surfaces decorated with vertically aligned nanostructures as a simple model system. High resolution live cell imaging of co-transfected U2OS cells expressing pCMV-LifeActGFP and pTAGRFP-Vinculin have been used to study the influence of nanopillar arrays on actin cytoskeleton focal adhesion organisation. Our present results indicate that the U2OS cells spreading on surfaces decorated with nanopillars can be categorised into three different regimes by how they respond to the nano-structures. These observed changes are quantified by analysing more than 400 high-resolution images, and indicate that tuning geometrical properties of the nanostructured surface can be used to direct cell behaviour.

More specifically, the U2OS cells were found to either contact the substrate, attach preferably around the cell edge, or be fully suspended on top of the vertical NP arrays. In the latter case, we hypothesise that the resulting reorganisation of FA and cytoskeleton is an effect analogous to what is seen for softer substrates.

Increased understanding of how cells behave on nanostructured surfaces, such as pillar arrays, could help us discover more details about complex cellular processes. For example, it is still poorly understood how changes in the actin cytoskeleton and its architecture influence cell signalling. By studying the cell response on nanostructured surfaces in a systematic way, the potential connection between actin cytoskeleton, cell adhesions and a plethora of biochemical signalling pathways could be further explored. We therefore envision that further development of the presented platform and analysis could have implications for advanced in vitro applications or for development of smarter in vivo biointerfaces.

\section{Methods}

\section{Fabrication of Nanostructures and Sample Mounting}

SU-8 nanostructures were fabricated as previously explained [63]. Briefly, $24 \mathrm{~mm}$ by $24 \mathrm{~mm}$ glass cover slips (\#1.5, Menzel-Gläser, thickness $170 \mu \mathrm{m}$ ) were cleaned by immersion in acetone, isopropyl alcohol, rinsed in deionised water and dried. The cover slips were then oxygen plasma treated for 2 min (Diener Femto plasma cleaner, power $100 \mathrm{~W}$, base pressure 0.3 torr), followed by dehydration for $10 \mathrm{~min}$ on a $150{ }^{\circ} \mathrm{C}$ hot plate. Samples were then placed in a desiccator containing an open vial of Hexamethyldisilazane (HMDS, Sigma Aldrich product no: 440191). HMDS was applied by vapour deposition, the desiccator was pumped to low vacuum using a diaphragm pump for $5 \mathrm{~min}$ and the samples were kept in HMDS atmosphere for $60 \mathrm{~min}$.

Substrates for EBL were prepared directly after HMDS treatment by spin coating SU-8 2001 (Microchem Corp.) to a desired thickness of $500 \mathrm{~nm}$ and $1000 \mathrm{~nm}$. SU-8 was made fluorescent by adding either Oxazine 170 perchlorate, Rhodamine 800 or Coumarin 102 (all Sigma Aldrich) to a final concentration of $100 \mu \mathrm{g} \mathrm{mL}^{-1}$ resist. After spin coating samples were dehydrated on a hot plate at $95{ }^{\circ} \mathrm{C}$. To mitigate charging during EBL exposure samples were then covered by a layer of conductive polymer AR-PC 5091 Electra 92 (AllResist $\mathrm{GmbH}$ ) by spin coating at $2000 \mathrm{rpm}$ for $60 \mathrm{~s}$ to thickness of $50 \mathrm{~nm}$.

An Elionix ELS-G100 $100 \mathrm{kV}$ EBL-system was used to fabricate SU-8 nanopillars (NPs) with processing parameters as described in our previous work [63]. Table 1 summarise the arrays fabricated for this work. Pillar arrays were exposed using the Elionix dot-pattern generator where each pillar is exposed in a single exposure. Arrays were exposed over an area of $2000 \mu \mathrm{m}$ by $4000 \mu \mathrm{m}$, with a current of $500 \mathrm{pA}$ in write fields of $500 \mu \mathrm{m}$ by $500 \mu \mathrm{m}$. NPs had a tip diameter of about $100 \mathrm{~nm}$ as a base diameter of $150 \mathrm{~nm}$ and $200 \mathrm{~nm}$ for structures of length $500 \mathrm{~nm}$ and $1000 \mathrm{~nm}$ respectively.

After EBL exposure, the samples were rinsed in DIwater to remove the conductive polymer, then post exposure baked for $2.3 \mathrm{~min}$ at $95{ }^{\circ} \mathrm{C}$ and developed twice in mr-Dev 600 (Micro Resist Technology GmbH) developer for $20 \mathrm{~s}$, rinsed in isopropyl alcohol and dried. Samples were then treated with oxygen plasma (Diener Femto plasma cleaner, power $50 \mathrm{~W}$, base pressure 0.3 torr) for $30 \mathrm{~s}$ to render SU-8 hydrophilic and to give it similar surface chemistry as glass by oxidising surface epoxy-groups to hydroxyl.

Fabricated structures were imaged using Scanning electron microscopy (SEM) and samples sputter coated with $5 \mathrm{~nm}$ Platinum/Palladium alloy deposited with a 208 HR B sputter coater (Cressington Scientific Instruments UK). SEM was performed with a FEI Apreo SEM, at $5 \mathrm{kV}$ and $0.2 \mathrm{nA}$ with sample $45^{\circ}$ pre-titled stage and with additional tilting of $30^{\circ}$.

When exposing the pillars, an indexing system was also exposed to make navigation during live-cell imaging more reliable. Arrays were optically inspected after fabrication to ensure free and standing pillars. The short Oxygen plasma treatment to render the SU-8 structures did not lead to any optically visible change to the structures. Lastly, the samples were mounted underneath $35 \mathrm{~mm}$ diameter dishes (Cellvis, Mountain View, CA, USA) with 
$14 \mathrm{~mm}$ holes and nano-structures pointing upwards, as indicated schematically in Fig. 7. As flat surfaces, areas outside the structured part of the same samples were used. Before usage, all dishes were disinfected with 70\% ethanol twice and dried.

\section{Cell Culture and Transfection}

U2OS-cells (ATCC) were cultivated in Dulbecco's modified Eagle's Medium (DMEM Prod. 41965039, Fischer Scientific) with $10 \%$ fetal bovine serum (FBS) and kept at $5 \% \mathrm{CO}_{2}$ and $37{ }^{\circ} \mathrm{C}$. Before detachment, cells were washed with PBS and detached with Trypsin-ethylenediaminetetraacetic acid (trypsin-EDTA) and seeded on nanostrucutred or flat surfaces. For the diameter $14 \mathrm{~mm}$ glass wells 15,000 cells were seeded.

For the standard transfection experiments, cells were allowed $6 \mathrm{~h}$ for adhering to surfaces before transfection. U2OS cells were transiently transfected using Lipofectamine 2000 (Invitrogen, Fischer Scientific) by adapting the manufacturer protocol to our system. Briefly, $2 \mu \mathrm{L}$ Lipofectamine 2000 was added to $50 \mu \mathrm{L}$ Opti-MEM I Reduced Serum Media (Prod. 11058021, Gibco , Fischer Scientific) and incubated for $5 \mathrm{~min}$ at room temperature. Plasmid DNA coding for fluorescent LifeAct-TagGFP2 and TagRFP-vinculin fusion proteins were co-transfected by using $0.5 \mu \mathrm{g}$ plasmid DNA (vinculin-pTagRFP and pCMVLifeAct plasmids) was diluted in $50 \mu \mathrm{L}$ Opti-MEM I and incubated at room temperature for $5 \mathrm{~min}$. For co-transfection of TagRFP-vinculin and pCMVLifeAct $0.5 \mu \mathrm{g}$ of each plasmid was used.

The diluted DNA was added to the diluted Lipofectamine 2000 in a 1:1 ratio, and left to incubate for $20 \mathrm{~min}$ at room temperature. $40 \mu \mathrm{L}$ of the combined transfection complex was then added to each well. After
18 h, 1.5 mL DMEM (Prod. 41965039) supplemented with $10 \%$ FBS and 1\% 10000U/mL Penicillin-Streptomycin was added to each dish.

For reverse transfection experiments, the same amounts of reactants were used, but the transfection complex was added to a suspension of U2OS cells, and the suspension was then added to the wells.

\section{Microscopy}

Live cell imaging was performed usin g a Zeiss LSM 800 Airyscan with an inverted Axio Observer Z1 stand connect to a PeCon compact incubator. Imaging was performed in an humidified environment at $37{ }^{\circ} \mathrm{C}$, with $5 \% \mathrm{CO}_{2}$ flow. High resolution imaging was performed using a Zeiss Plan-Apochromat 63x/1.4NA DIC M27 oil objective with Cargille Immersion Oil Type 37 ( $n=$ 1.51) suited for use at $37^{\circ} \mathrm{C}$. All images were taken using the system optimised pixel size both in-plane (typically $34 \mathrm{~nm}$ ) and for stacks in the vertical axis (typically $180 \mathrm{~nm})$.

To minimise imaging bias, imaging was performed in a standardised manner where each pillar array was raster scanned and cells expressing both LifeActGFP and Vinculin RFP were imaged. The high resolution images were then processed using a Zeiss algorithm for reconstruction of AiryScan images and exported as CZI-files for further manual and automatised image processing.

\section{Image Analysis}

For all cells, cell shape was based on the expression LifeActGFP fusion protein and expression of TagRFP-vinculin was used to identify FAs. Segmentation of images was performed using a script written in Python 3 [72] using CZIfile [73] (version 2017.09.12) for reading the
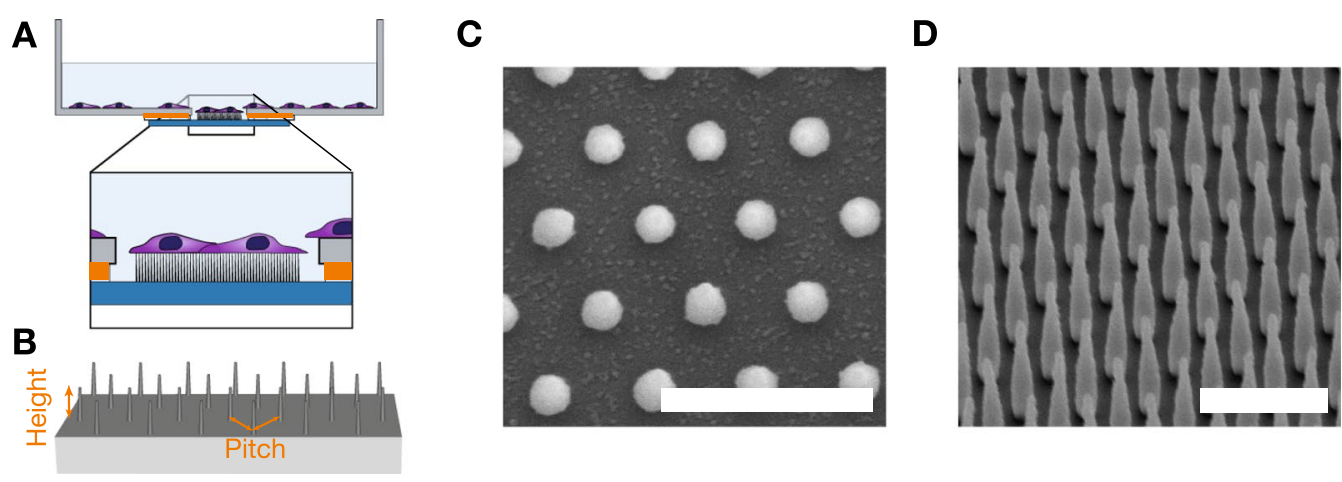

Fig. 7 A Side view schematic representation of nano-structured surface mounted in petri dish. Glass slides are mounted using paraffin such that structures are pointing upwards. B Tilted schematic representation of nano-pillar array on flat surface, and two important parameters for the nano-pillar arrays (height and pitch). These figures are not drawn to scale. C, D Overview of the nanopillar arrays employed in this work. Top-down and tilted side-view scanning electron micrographs of fabricated nano-pillar array with pillars of height $1000 \mathrm{~nm}$ and pitch $1000 \mathrm{~nm}$. Scalebars $2000 \mathrm{~nm}$ 
microscopy images in Zeiss-format. The python packages Scipy [74] and Scikit-image [75] were used for multidimensional image processing and image segmentation respectively.

To reduce the influence from fluorescence cross-talk from pillars (due to Oxazine 170 perchlorate, Rhodamine 800 or Coumarin 102), the pillar/surface channel was used as a background and subtracted from the TagRFPvinculin imaging channel. A median filter (size: 10 pixels) was applied to remove noise from the TagRFP-vinculin channel, followed by classification of the image into regions based on their intensity value using a Multi-Otsu approach. Multi-Otsu thresholding with three classes was applied. The first class was typically the background, the second class constituted the cytosolic vinculin, whereas vinculin rich areas in FAs appeared brighter and could be classified into a third class. The quality of the image segmentation was briefly assessed by comparison to manual segmentation.

Area of cells and vinculin rich regions were described by counting pixel numbers and from this the actual area was found by correcting for the pixel size. Shape geometries were described by fitting each region with an ellipse with the same second-moment as the segmented region. In order to describe the cell area geometry, three measures were used: (1) Aspect ratio defined as the ratio of the ellipse major axis to the minor axis. (2) Circularity given as,

$$
C=\frac{4 \pi * \text { Area }}{\text { Perimeter }^{2}}
$$

and roundness given as,

$$
R=\frac{4 * \text { Area }}{\pi * \text { MajorAxis }^{2}} .
$$

Segmented vinculin areas with a fitted ellipse that were too round (aspect ratio $\leq 1.5$ ) or too elongated (aspect ratio $\geq 8.5$ ) were rejected. In addition, vinculin areas smaller than $0.05 \mu \mathrm{m}^{2}$ were filtered out. In order to find the distance between each vinculin area and the cell edge, the shortest euclidean distance between each centroid (the centre of the fitted ellipse for each vinculin area) and the cell edge was calculated.

\section{Statistical Analysis}

Statistical comparisons of distributions were performed by using the non-parametric two-tailed Mann-Whitney test neither assuming normal distribution nor equal standard deviation. $P$-values $\geq 0.05$ were considered to represent a non-significant (ns) difference between the two populations. Significant values were denoted with * for $p$ in 0.01 to $0.05,{ }^{* * *}$ for $p$ in 0.001 to $0.01,{ }^{* * * *}$ for $p$ in 0.0001 to 0.001 and lastly ${ }^{* * * * *}$ for $p \leq 0.0001$.

\section{Abbreviations}

DMEM: Dulbecco's Modified Eagle's Medium; EBL: Electron Beam Lithography; ECM: Extracellular Matrix; EDTA: Ethylenediaminetetraacetic Acid; FA: Focal Adhesion; FBS: Fetal Bovine Serum; GFP: Green Fluorescent Protein; HMDS: Hexamethyldisilazane; NP: Nanopillar; RFP: Red Fluorescent Protein; SEM: Scanning Electron Microscopy.

\section{Acknowledgements \\ Irene Persiconi (Department of Biosciences, $\mathrm{UiO}$ ) is acknowledged for help with initial cell experiments.}

\section{Authors' Contributions}

J.V. fabricated nanostructures. J.V. and N.A.G. developed experimental protocols for cell work. J.V. performed cell experiments and confocal imaging. J.V. and P.S. wrote the text. All authors contributed in discussion and revision of the manuscript. All authors read and approved the final manuscript.

Funding

The Research Council of Norway is acknowledged for the support to the Norwegian Micro- and Nano-Fabrication Facility, NorFab, Project No. 295864.

\section{Declarations}

\section{Consent for Publication}

All authors consent to the publication of this manuscript.

\section{Competing interests}

The authors declare that they have no competing interests.

\section{Author details}

${ }^{1}$ Department of Physics, Norwegian University of Science and Technology (NTNU), Trondheim, Norway. ${ }^{2}$ Department of Biosciences, University of Oslo (UiO), Oslo, Norway. ${ }^{3}$ Present Address: Department of Electronic Systems,

Norwegian University of Science and Technology (NTNU), Trondheim, Norway.

Received: 22 June 2021 Accepted: 28 August 2021

Published online: 15 September 2021

\section{References}

1. Frantz C, Stewart KM, Weaver VM (2010) The extracellular matrix at a glance. J Cell Sci 123(24):4195-4200. https://doi.org/10.1242/jcs.023820

2. Stevens MM (2005) Exploring and engineering the cell surface interface. Science 310(5751):1135-1138. https://doi.org/10.1126/science.1106587

3. Mirbagheri M, Adibnia V, Hughes BR, Waldman SD, Banquy X, Hwang DK (2019) Advanced cell culture platforms: a growing quest for emulating natural tissues. Mater Horiz 6(1):45-71. https://doi.org/10.1039/c8mh0 0803e

4. Cukierman E, Pankov R, Stevens DR, Yamada KM (2001) Taking cell-matrix adhesions to the third dimension. Science 294(5547):1708-1712. https:// doi.org/10.1126/science.1064829

5. Grinnell F, Petroll WM (2010) Cell motility and mechanics in three-dimensional collagen matrices. Annu Rev Cell Dev Biol 26(1):335-361. https:// doi.org/10.1146/annurev.cellbio.042308.113318

6. Baker BM, Chen CS (2012) Deconstructing the third dimension-how 3D culture microenvironments alter cellular cues. J Cell Sci 125(13):30153024. https://doi.org/10.1242/jcs.079509

7. Huang H, Ding Y, Sun XS, Nguyen TA (2013) Peptide hydrogelation and cell encapsulation for 3D culture of MCF-7 breast cancer cells. PLoS ONE 8(3):59482. https://doi.org/10.1371/journal.pone.0059482

8. Jensen C, Teng Y (2020) Is it time to start transitioning from 2D to 3D cell culture? Front Mol Biosci 7(March):1-15. https://doi.org/10.3389/fmolb. 2020.00033 
9. LiY, Kilian KA (2015) Bridging the gap: from 2D cell culture to 3D microengineered extracellular matrices. Adv Healthcare Mater 4(18):2780-2796. https://doi.org/10.1002/adhm.201500427

10. Lou J, Stowers R, Nam S, Xia Y, Chaudhuri O (2018) Stress relaxing hyaluronic acid-collagen hydrogels promote cell spreading, fiber remodeling, and focal adhesion formation in 3D cell culture. Biomaterials 154:213222. https://doi.org/10.1016/j.biomaterials.2017.11.004

11. Campuzano S, Pelling AE (2019) Scaffolds for 3D cell culture and cellular agriculture applications derived from non-animal sources. Front Sustain Food Syst 3(38):1-9. https://doi.org/10.3389/fsufs.2019.00038

12. Ogaki R, Alexander M, Kingshott $P$ (2010) Chemical patterning in biointerface science. Mater Today 13(4):22-35. https://doi.org/10.1016/S1369$7021(10) 70057-2$

13. Hortigüela V, Larrañaga E, Lagunas A, Acosta GA, Albericio F, Andilla J, Loza-Alvarez P, Martínez E (2019) Large-area biomolecule nanopatterns on diblock copolymer surfaces for cell adhesion studies. Nanomaterials 9(4):579. https://doi.org/10.3390/nano9040579

14. Zhou S, Metcalf KJ, Bugga P, Grant J, Mrksich M (2018) Photoactivatable reaction for covalent nanoscale patterning of multiple proteins. ACS Appl Mater Interfaces 10(47):40452-40459. https://doi.org/10.1021/acsami. 8 b 16736

15. Yeh YC, Ling JY, Chen WC, Lin HH, Tang MJ (2017) Mechanotransduction of matrix stiffness in regulation of focal adhesion size and number: reciprocal regulation of caveolin-1 and $\beta 1$ integrin. Sci Rep 7(1):1-14. https:// doi.org/10.1038/s41598-017-14932-6

16. Girard YK, Wang C, Ravi S, Howell MC, Mallela J, Alibrahim M, Green R, Hellermann G, Mohapatra SS, Mohapatra S (2013) A 3D fibrous Scaffold inducing tumoroids: a platform for anticancer drug development. PLOS ONE 8(10):75345. https://doi.org/10.1371/journal.pone.0075345

17. Anselme K, Ploux L, Ponche A (2010) Cell/material interfaces: influence of surface chemistry and surface topography on cell adhesion. J Adhes Sci Technol 24(5):831-852. https://doi.org/10.1163/016942409X1259823156 8186

18. Higgins SG, Becce M, Belessiotis-Richards A, Seong H, Sero JE, Stevens MM (2020) High-aspect-ratio nanostructured surfaces as biological metamaterials. Adv Mater 32(9):1-44. https://doi.org/10.1002/adma.20190 3862

19. Place ES, Evans ND, Stevens MM (2009) Complexity in biomaterials for tissue engineering. Nat Mater 8(6):457-470. https://doi.org/10.1038/nmat2 441

20. Weibel DB, DiLuzio WR, Whitesides GM (2007) Microfabrication meets microbiology. Nat Rev Microbiol 5(3):209-218. https://doi.org/10.1038/ nrmicro1616

21. Mendes PM (2013) Cellular nanotechnology: making biological interfaces smarter. Chem Soc Rev 42(24):9207. https://doi.org/10.1039/c3cs60198f

22. Pampaloni F, Reynaud EG, Stelzer EHK (2007) The third dimension bridges the gap between cell culture and live tissue. Nat Rev Mol Cell Biol 8(10):839-845. https://doi.org/10.1038/nrm2236

23. Gurski LA, Petrelli NJ, Jia X, Farach-Carson MC (2010) 3D matrices for anticancer drug testing and development. Oncol Issues 25(1):20-25. https:// doi.org/10.1080/10463356.2010.11883480

24. Langhans SA (2018) Three-dimensional in vitro cell culture models in drug discovery and drug repositioning. Front Pharmacol 9(JAN):6. https:// doi.org/10.3389/fphar.2018.00006

25. Wang J, Chen A, Lieu DK, Karakikes I, Chen G, Keung W, Chan CW, Hajjar RJ, Costa KD, Khine M, Li RA (2013) Effect of engineered anisotropy on the susceptibility of human pluripotent stem cell-derived ventricular cardiomyocytes to arrhythmias. Biomaterials 34(35):8878-8886. https://doi.org/ 10.1016/.j.biomaterials.2013.07.039

26. Luna Jl, Ciriza J, Garcia-Ojeda ME, Kong M, Herren A, Lieu DK, Li RA, Fowlkes CC, Khine M, McCloskey KE (2011) Multiscale biomimetic topography for the alignment of neonatal and embryonic stem cell-derived heart cells. Tissue Eng - Part C: Methods 17(5):579-588. https://doi.org/10. 1089/ten.tec.2010.0410

27. Sun Z, Costell M, Fässler R (2019) Integrin activation by Talin, Kindlin and mechanical forces. Nat Cell Biol 21(1):25-31. https://doi.org/10.1038/ s41556-018-0234-9

28. Ezzell RM, Goldmann WH, Wang N, Parasharama N, Ingber DE (1997) Vinculin promotes cell spreading by mechanically coupling integrins to the cytoskeleton. Exp Cell Res 231(1):14-26. https://doi.org/10.1006/excr. 1996.3451
29. Thompson PM, Tolbert CE, Shen K, Kota P, Palmer SM, Plevock KM, Orlova A, Galkin VE, Burridge K, Egelman EH, Dokholyan NV, Superfine R, Campbell SL (2014) Identification of an actin binding surface on vinculin that mediates mechanical cell and focal adhesion properties. Structure 22(5):697-706. https://doi.org/10.1016/j.str.2014.03.002

30. Thievessen I, Thompson PM, Berlemont S, Plevock KM, Plotnikov SV, Zemljic-Harpf A, Ross RS, Davidson MW, Danuser G, Campbell SL, Waterman CM (2013) Vinculin-actin interaction couples actin retrograde flow to focal adhesions, but is dispensable for focal adhesion growth. J Cell Biol 202(1):163-177. https://doi.org/10.1083/jcb.201303129

31. Mierke CT, Kollmannsberger P, Zitterbart DP, Smith J, Fabry B, Goldmann WH (2008) Mechano-coupling and regulation of contractility by the vinculin tail domain. Biophys J 94(2):661-670. https://doi.org/10.1529/ biophysj.107.108472

32. Tolbert CE, Burridge K, Campbell SL (2013) Vinculin regulation of F-actin bundle formation. Cell Adhes Migr 7(2):219-225. https://doi.org/10.4161/ cam. 23184

33. Tolbert CE, Thompson PM, Superfine R, Burridge K, Campbell SL (2014) Correction to phosphorylation at Y1065 in vinculin mediates actin bundling, cell spreading, and mechanical responses to force. Biochemistry 53(39):6286. https://doi.org/10.1021/bi501135k

34. Shen K, Tolbert CE, Guilluy C, Swaminathan VS, Berginski ME, Burridge K, Superfine R, Campbell SL (2011) The vinculin C-terminal hairpin mediates $\mathrm{F}$-actin bundle formation, focal adhesion, and cell mechanical properties. J Biol Chem 286(52):45103-45115. https://doi.org/10.1074/jbc.M111 . 244293

35. Wen KK, Rubenstein PA, DeMali KA (2009) Vinculin nucleates actin polymerization and modifies actin filament structure. J Biol Chem 284(44):30463-30473. https://doi.org/10.1074/jbc.M109.021295

36. Le Clainche C, Dwivedi SP, Didry D, Carlier MF (2010) Vinculin is a dually regulated actin filament barbed end-capping and side-binding protein J Biol Chem 285(30):23420-23432. https://doi.org/10.1074/jbc.M110. 102830

37. DeMali KA, Barlow CA, Burridge K (2002) Recruitment of the Arp2/3 complex to vinculin: coupling membrane protrusion to matrix adhesion. J Cell Biol 159(5):881-891. https://doi.org/10.1083/jcb.200206043

38. Rhee $\mathrm{S}$, Jiang $\mathrm{H}, \mathrm{Ho} \mathrm{C}-\mathrm{H}$, Grinnell $\mathrm{F}$ (2007) Microtubule function in fibroblast spreading is modulated according to the tension state of cellmatrix interactions. Proc Natl Acad Sci 104(13):5425-5430. https://doi. org/10.1073/pnas.0608030104

39. Yamada KM, Sixt M (2019) Mechanisms of 3D cell migration. Nat Rev Mol Cell Biol 20(12):738-752. https://doi.org/10.1038/s41580-019-0172-9

40. Fraley SI, Feng Y, Krishnamurthy R, Kim DH, Celedon A, Longmore GD, Wirtz D (2010) A distinctive role for focal adhesion proteins in threedimensional cell motility. Nat Cell Biol 12(6):598-604. https://doi.org/10 1038/ncb2062

41. Stolarska MA, Rammohan AR (2017) Center or periphery? Modeling the effects of focal adhesion placement during cell spreading. PLOS ONE 12(2):1-22. https://doi.org/10.1371/journal.pone.0171430

42. Zaman MH, Trapani LM, Sieminski AL, MacKellar D, Gong H, Kamm RD, Wells A, Lauffenburger DA, Matsudaira P (2006) Migration of tumor cells in $3 \mathrm{D}$ matrices is governed by matrix stiffness along with cell-matrix adhesion and proteolysis. Proc Natl Acad Sci 103(29):10889-10894. https://doi.org/10.1073/pnas.0604460103

43. Sapudom J, Rubner S, Martin S, Kurth T, Riedel S, Mierke CT, Pompe T (2015) The phenotype of cancer cell invasion controlled by fibril diameter and pore size of 3D collagen networks. Biomaterials 52(1):367-375. https://doi.org/10.1016/j.biomaterials.2015.02.022

44. Xie J, Bao M, Bruekers SMC, Huck WTS (2017) Collagen gels with different fibrillar microarchitectures elicit different cellular responses. ACS Appl Mater Interfaces 9(23):19630-19637. https://doi.org/10.1021/acsami. 7 b03883

45. Beckwith KS, Ullmann S, Vinje J, Sikorski P (2019) Influence of nanopillar arrays on fibroblast motility, adhesion, and migration mechanisms. Small 15(43):1902514. https://doi.org/10.1002/smll.201902514

46. McGuire AF, Santoro F, Cui B (2018) Interfacing cells with vertical nanoscale devices: applications and characterization. Annu Rev Anal Chem 11(1):101-126. https://doi.org/10.1146/annur ev-anchem-061417-125705

47. Bonde S, Buch-Månson N, Rostgaard KR, Andersen TK, Berthing T, Martinez KL (2014) Exploring arrays of vertical one-dimensional 
nanostructures for cellular investigations. Nanotechnology 25(36):362001. https://doi.org/10.1088/0957-4484/25/36/362001

48. Beckwith KS, Cooil SP, Wells JW, Sikorski P (2015) Tunable high aspect ratio polymer nanostructures for cell interfaces. Nanoscale 7(18):8438-8450. https://doi.org/10.1039/C5NR00674K

49. Li X, Matino L, Zhang W, Klausen L, McGuire A, Lubrano C, Zhao W, Santoro F, Cui B (2019) A nanostructure platform for live cell manipulation of membrane curvature. Nat Protoc 14(6):1772. https://doi.org/10.1038/ s41596-019-0161-7

50. Prinz CN (2015) Interactions between semiconductor nanowires and living cells. J Phys: Condens Matter 27(23):233103. https://doi.org/10.1088/ 0953-8984/27/23/233103

51. Rostgaard KR, Frederiksen RS, Liu Y-CC, Berthing T, Madsen MH, Holm J, Nygård J, Martinez KL (2013) Vertical nanowire arrays as a versatile platform for protein detection and analysis. Nanoscale 5(21):10226. https:// doi.org/10.1039/c3nr03113f

52. Dipalo M, McGuire AF, Lou H-Y, Caprettini V, Melle G, Bruno G, Lubrano C, Matino L, Li X, De Angelis F, Cui B, Santoro F (2018) Cells adhering to $3 \mathrm{D}$ vertical nanostructures: cell membrane reshaping without stable internalization. Nano Lett 18(9):6100-6105. https://doi.org/10.1021/acs. nanolett.8b03163

53. Dai J, Gong J, Kong N, Yao Y (2020) Cellular architecture response to aspect ratio tunable nanoarrays. Nanoscale 12(23):12395-12404. https:// doi.org/10.1039/d0nr01003k

54. Xie X, Xu AM, Leal-Ortiz S, Cao Y, Garner CC, Melosh NA (2013) Nanostrawelectroporation system for highly efficient intracellular delivery and transfection. ACS Nano 7(5):4351-4358. https://doi.org/10.1021/nn400 $874 a$

55. Peer E, Artzy-Schnirman A, Gepstein L, Sivan U (2012) Hollow nanoneedle array and its utilization for repeated administration of biomolecules to the same cells. ACS Nano 6(6):4940-4946. https://doi.org/10.1021/nn300 $443 \mathrm{~h}$

56. Na Y-R, Kim SY, Gaublomme JT, Shalek AK, Jorgolli M, Park H, Yang EG (2013) Probing enzymatic activity inside living cells using a nanowire-cell "Sandwich" assay. Nano Lett 13(1):153-158. https://doi.org/10.1021/nl303 7068

57. Hanson L, Zhao W, Lou HY, Lin ZC, Lee SW, Chowdary P, Cui Y, Cui B (2015) Vertical nanopillars for in situ probing of nuclear mechanics in adherent cells. Nat Nanotechnol 10(6):554-562. https://doi.org/10.1038/nnano. 2015.88

58. Lou HY, Zhao W, Li X, Duan L, Powers A, Akamatsu M, Santoro F, McGuire AF, Cui Y, Drubin DG, Cui B (2019) Membrane curvature underlies actin reorganization in response to nanoscale surface topography. Proc Natl Acad Sci USA 116(46):23143-23151. https://doi.org/10.1073/pnas.19101 66116

59. Lou HY, Zhao W, Zeng Y, Cui B (2018) The role of membrane curvature in nanoscale topography-induced intracellular signaling. Acc Chem Res 51(5):1046-1053. https://doi.org/10.1021/acs.accounts.7b00594

60. Zhao W, Hanson L, Lou HY, Akamatsu M, Chowdary PD, Santoro F, Marks JR, Grassart A, Drubin DG, Cui Y, Cui B (2017) Nanoscale manipulation of membrane curvature for probing endocytosis in live cells. Nat Nanotechnol 12(8):750-756. https://doi.org/10.1038/nnano.2017.98

61. Li Z, Persson H, Adolfsson K, Oredsson S, Prinz CN (2018) Morphology of living cells cultured on nanowire arrays with varying nanowire densities and diameters. Sci China Life Sci 61(4):427-435. https://doi.org/10.1007/ s11427-017-9264-2

62. Buch-Månson N, Kang DH, Kim D, Lee KE, Yoon MH, Martinez KL (2017) Mapping cell behavior across a wide range of vertical silicon nanocolumn densities. Nanoscale 9(17):5517-5527. https://doi.org/10.1039/c6nro $9700 f$

63. Vinje J, Beckwith KS, Sikorski P (2020) Electron beam lithography fabrication of SU-8 polymer structures for cell studies. J Microelectromech Syst 29(2):160-169. https://doi.org/10.1109/JMEMS.2020.2967174

64. Bonde S, Bolinsson J, Berthing T, Martinez KL (2015) Towards a better prediction of cell settling on nanostructure arrays - simple means to complicated ends. Adv Funct Mater 25(21):3246-3255. https://doi.org/10 1002/adfm.201500399

65. Huff J, Bergter A, Birkenbeil J, Kleppe I, Engelmann R, Krzic U (2017) The new 2D superresolution mode for ZEISS Airyscan. Nat Methods 14(12):1223. https://doi.org/10.1038/nmeth.f.404

66. Livne A, Geiger B (2016) The inner workings of stress fibers-from contractile machinery to focal adhesions and back. J Cell Sci 129(7):12931304. https://doi.org/10.1242/jcs.180927

67. Prager-Khoutorsky M, Lichtenstein A, Krishnan R, Rajendran K, Mayo A Kam Z, Geiger B, Bershadsky AD (2011) Fibroblast polarization is a matrixrigidity-dependent process controlled by focal adhesion mechanosensing. Nat Cell Biol 13(12):1457-1465. https://doi.org/10.1038/ncb2370

68. Xie X, Aalipour A, Gupta SV, Melosh NA (2015) Determining the time window for dynamic nanowire cell penetration processes. ACS Nano 9(12):11667-11677. https://doi.org/10.1021/acsnano.5b05498

69. Verma A, Stellacci F (2010) Effect of surface properties on nanoparticlecell interactions. Small 6(1):12-21. https://doi.org/10.1002/smll.20090 1158

70. Verma P, Wong IY, Melosh NA (2010) Continuum model of mechanical interactions between biological cells and artificial nanostructures. Biointerphases 5(2):37-44. https://doi.org/10.1116/1.3431960

71. Xie X, Xu AM, Angle MR, Tayebi N, Verma P, Melosh NA (2013) Mechanical model of vertical nanowire cell penetration. Nano Lett 13(12):6002-6008. https://doi.org/10.1021/nl403201a

72. Van Rossum G, Drake FL (2009) Python 3 reference manual, vol CreateSpac. CreateSpace, Scotts Valley, CA

73. Gohlke C (2017) czifile. Irvine, CA

74. Virtanen P, Gommers R, Oliphant TE, Haberland M, Reddy T, Cournapeau D, Burovski E, Peterson P, Weckesser W, Bright J, van der Walt SJ, Brett M, Wilson J, Millman KJ, Mayorov N, Nelson ARJ, Jones E, Kern R, Larson E, Carey CJ, Polat I, Feng Y, Moore EW, VanderPlas J, Laxalde D, Perktold J, Cimrman R, Henriksen I, Quintero EA, Harris CR, Archibald AM, Ribeiro AH, Pedregosa $F$, van Mulbregt $P$ (2020) SciPy 1.0: fundamental algorithms for scientific computing in Python. Nat Methods 17(3):261-272. https://doi. org/10.1038/s41592-019-0686-2. arXiv:1907.10121

75. Van Der Walt S, Schoenberger JL, Nunez-Iglesias J, Boulogne F, Warner JD, Yager N, Gouillart E, YU T (2014) Scikit-image: image processing in python. PeerJ 2014(1):453. https://doi.org/10.7717/peerj.453

\section{Publisher's Note}

Springer Nature remains neutral with regard to jurisdictional claims in published maps and institutional affiliations. 